\title{
Bedside monitoring of lung volume available for gas exchange
}

\author{
Minh C. Tran ${ }^{1,2^{*}}$, Douglas C. Crockett ${ }^{1}$, John N. Cronin ${ }^{3,4}$, João Batista Borges ${ }^{3}$, Göran Hedenstierna ${ }^{5}$, \\ Anders Larsson ${ }^{6}$, Andrew D. Farmery ${ }^{1}$ and Federico Formenti ${ }^{1,3,7^{*}}$ (1)
}

\author{
*Correspondence: \\ minh.tran@chch.ox.ac.uk; \\ federico.formenti@outlook. \\ com \\ ${ }^{1}$ Nuffield Division \\ of Anaesthetics, University \\ of Oxford, Oxford, UK \\ Full list of author information \\ is available at the end of the \\ article
}

\begin{abstract}
Background: Bedside measurement of lung volume may provide guidance in the personalised setting of respiratory support, especially in patients with the acute respiratory distress syndrome at risk of ventilator-induced lung injury. We propose here a novel operator-independent technique, enabled by a fibre optic oxygen sensor, to quantify the lung volume available for gas exchange. We hypothesised that the continuous measurement of arterial partial pressure of oxygen $\left(\mathrm{PaO}_{2}\right)$ decline during a breath-holding manoeuvre could be used to estimate lung volume in a single-compartment physiological model of the respiratory system.
\end{abstract}

Methods: Thirteen pigs with a saline lavage lung injury model and six control pigs were studied under general anaesthesia during mechanical ventilation. Lung volumes were measured by simultaneous $\mathrm{PaO}_{2}$ rate of decline $\left(\mathrm{V}_{\mathrm{PaO}_{2}}\right)$ and whole-lung computed tomography scan $\left(V_{C T}\right)$ during apnoea at different positive end-expiratory and end-inspiratory pressures.

Results: A total of 146 volume measurements was completed (range 134 to $1869 \mathrm{~mL}$ ). A linear correlation between $V_{C T}$ and $V_{\mathrm{PaO} 2}$ was found both in control (slope $=0.9$, $R^{2}=0.88$ ) and in saline-lavaged pigs (slope $=0.64, R^{2}=0.70$ ). The bias from Bland-Altman analysis for the agreement between the $V_{\mathrm{CT}}$ and $V_{\mathrm{PaO} 2}$ was $-84 \mathrm{~mL}$ (limits of agreement $\pm 301 \mathrm{~mL}$ ) in control and $+2 \mathrm{~mL}$ (LoA $\pm 406 \mathrm{~mL}$ ) in saline-lavaged pigs. The concordance for changes in lung volume, quantified with polar plot analysis, was $-4^{\circ}$ $\left(\right.$ LoA $\left.\pm 19^{\circ}\right)$ in control and $-9^{\circ}\left(\right.$ LoA $\left.\pm 33^{\circ}\right)$ in saline-lavaged pigs.

Conclusion: Bedside measurement of $\mathrm{PaO}_{2}$ rate of decline during apnoea is a potential approach for estimation of lung volume changes associated with different levels of airway pressure.

Keywords: Computed tomography, Lung volume, Arterial oxygen partial pressure

\section{Background}

The acute respiratory distress syndrome (ARDS) is a common condition affecting about 100,000 patients yearly in the European Union and has a high mortality rate of $\sim 40 \%$, with ARDS patients occupying 10\% of intensive care unit beds in the UK [1]. ARDS patients require mechanical ventilation to maintain blood gases within the desired range. Despite low tidal volumes and limited plateau pressures being associated with author(s) and the source, provide a link to the Creative Commons licence, and indicate if changes were made. The images or other third party material in this article are included in the article's Creative Commons licence, unless indicated otherwise in a credit line to the material. If material is not included in the article's Creative Commons licence and your intended use is not permitted by statutory regulation or exceeds the permitted use, you will need to obtain permission directly from the copyright holder. To view a copy of this licence, visit http:// creativecommons.org/licenses/by/4.0/. 
better outcomes, this lifesaving mechanical ventilation can paradoxically contribute to the high mortality by further damaging the lung [2]. Clinical trials aimed at reducing lung injury via the application of high positive end-expiratory pressure (PEEP) levels have demonstrated conflicting results [3], suggesting that similar ventilator settings do not produce the same response at the alveolar level between different patients, especially in the presence of the "baby lung", a smaller lung volume available for ventilation [4]. This could also be the case in the presence of lung heterogeneity like in COVID-19, where very similar arterial partial pressure of oxygen $\left(\mathrm{PaO}_{2}\right)$ can be observed for very different computed tomography (CT) values [5-7]. There is a clear need for developments to enable individual titration of mechanical ventilation strategy, for example bedside real-time measurement of lung volume actually available for gas exchange, especially following changes between PEEP levels [8], which may contribute to the identification of patients with recruitable lungs.

Techniques currently available for the bedside measurement of lung volume are not routinely used because of different limitations including costs, physical dimensions, accuracy, time and conditions required for the measurement itself [9-11], although promising, operator-independent approaches are emerging [12-16].

In the presence of a single-compartment model of the lung, and for a known oxygen uptake, the rate of $\mathrm{PaO}_{2}$ decline during apnoea is inversely proportional to lung volume [17-19]. While the injured lung is highly heterogeneous in the dynamic state, this heterogeneity may be reduced after a few seconds of apnoea [20]. Continuous monitoring of $\mathrm{PaO}_{2}$ during breath-holding manoeuvres at the bedside may allow measurement of lung volume, and together with lung mechanics parameters, enable the calculation of lung strain ratio [21].

The aim of this study was to validate a novel method to determine lung volume available for gas exchange in real-time at the bedside by $\mathrm{PaO}_{2}$ rate of decline and oxygen uptake during apnoea. These measurements were performed at different positive endexpiratory and end-inspiratory pressures in mechanically ventilated pigs with saline lavage lung injury and in control pigs. Simultaneous whole-lung CT imaging data were used for comparison, where the lung volumes determined by $\mathrm{CT}$ would include regions with air trapped behind closed airways and aerated regions that are poorly perfused with blood, each of which would not contribute significantly to gas exchange, and could overlook regions with very limited aeration.

\section{Methods}

\section{Ethical approval}

The study was performed in a total of 19 domestic pigs (mean weight (SD) $=30$ (2) $\mathrm{kg}$ ) as part of different experiments at the Hedenstierna laboratory, Uppsala University, Sweden. The studies were approved by the regional animal welfare ethics committee (Ref: C98/16) and adhered to the Animal Research: Reporting of in vivo Experiments guidelines [22].

\section{Animal preparation and monitoring}

The animals' baseline characteristics are summarised in Table 1. Animals received intramuscular sedation and were anaesthetised with total intravenous anaesthesia as 
Table 1 Baseline characteristics for animals

\begin{tabular}{lcc}
\hline Parameters & Control $(\boldsymbol{n = 6 )}$ & $\begin{array}{c}\text { Saline lavage lung } \\
\text { injury model }(\boldsymbol{n}=\mathbf{1 3})\end{array}$ \\
\hline Weight $(\mathrm{kg})$ & $31(2)$ & $30(2)$ \\
Heart rate & $97(24)$ & $91(16)$ \\
$\mathrm{SBP}(\mathrm{mmHg})$ & $111(7)$ & $100(10)$ \\
$\mathrm{DBP}(\mathrm{mmHg})$ & $71(8)$ & $59(12)$ \\
$\mathrm{Cardiac}$ output $(\mathrm{L} / \mathrm{min})$ & $3.9(1.2)$ & $3.4(0.6)$ \\
$\mathrm{PASP}(\mathrm{mmHg})$ & $32(5)$ & $35(5)$ \\
$\mathrm{PADP}(\mathrm{mmHg})$ & $13(6)$ & $18(6)$ \\
$\mathrm{Hb}(\mathrm{g} / \mathrm{dL})$ & $84(9)$ & $84(7)$ \\
$\mathrm{F}_{1} \mathrm{O}_{2}$ & $0.4(0.1)$ & $0.8(0.1)$ \\
$\mathrm{SaO}$ & $(\%)$ & $95(7)$ \\
$\mathrm{pH}$ & $99(1)$ & $7.28(0.09)$ \\
$\mathrm{PaO}_{2}(\mathrm{kPa})$ & $7.42(0.03)$ & $16.4(7.5)$ \\
$\mathrm{PaCO}_{2}(\mathrm{kPa})$ & $19.9(3.2)$ & $8.5(2.1)$ \\
$\mathrm{PFR}_{(\mathrm{mmHg})}$ & $6.1(0.8)$ & $160(84)$ \\
\hline $\mathrm{Conto}$ & $425(100)$ &
\end{tabular}

Control animals and saline lavage lung injury model, mean (SD) are shown

SBP, systolic blood pressure; DBP, diastolic blood pressure; PASP, pulmonary artery systolic pressure; PADP, pulmonary artery diastolic blood pressure; $\mathrm{Hb}$, haemoglobin; $\mathrm{F}_{1} \mathrm{O}_{2}$, fraction of inspired $\mathrm{O}_{2} ; \mathrm{SaO}_{2}$, arterial oxygen saturation; $\mathrm{PaO}_{2}$, arterial $\mathrm{O}_{2}$ partial pressure; $\mathrm{PaCO}_{2}$, arterial $\mathrm{CO}_{2}$ partial pressure; $\mathrm{PFR}, \mathrm{PaO}_{2}: \mathrm{F}_{1} \mathrm{O}_{2}$ ratio

described elsewhere [23]. Mechanical ventilation was delivered at 20-25 breaths per minute with a tidal volume $\left(V_{\mathrm{T}}\right)$ of $10 \mathrm{~mL} / \mathrm{kg}$ and an inspiratory:expiratory ratio (I:E) of 1:2 (Servo-I, Maquet Critical Care, Solna, Sweden). Lack of spontaneous movements, absence of reaction to painful stimulation between the front hooves and absence of cardiovascular signs of sympathetic stimulation (increases in heart rate or arterial blood pressure) confirmed the depth of anaesthesia. Once anaesthesia was ascertained, rocuronium was administered for muscle relaxation. Continuous infusion of Ringerfundin ${ }^{\mathrm{TM}}$ solution (Braun Melsungen Ag, Melsungen, Germany) was used for fluid replacement at $10 \mathrm{~mL} / \mathrm{kg} / \mathrm{h}$ during the preparation and at $7 \mathrm{~mL} / \mathrm{kg} / \mathrm{h}$ thereafter. Cardiac output was monitored intermittently by pulmonary artery catheter thermodilution, together with arterio-mixed venous blood samples used to calculate oxygen uptake $\left(\dot{V}_{\mathrm{O}_{2}}\right)$ via the Fick's principle. Physiological parameters were continuously recorded with standard patient monitors (respiratory monitor: Datex Ohmeda Capnomac Ultima; multi-parameter patient monitor: Datex AS3) and electrical impedance tomography (EIT) to monitor pulmonary regional ventilation changes (Enlight, TIMPEL SA, São Paulo, Brazil). Analogue signals were continuously recorded on a computer via PowerLab (AD Instruments, New Zealand).

\section{Saline lavage lung injury model}

For this initial proof-of-concept study, a collapse-prone lung injury was induced with a technique modified from Lachmann and colleagues [24]. Mechanical ventilation with a fraction of inspired $\mathrm{O}_{2}\left(\mathrm{~F}_{\mathrm{I}} \mathrm{O}_{2}\right)$ of 1.0 preceded the disconnection of the ventilator and surfactant depletion via lung lavage with $30 \mathrm{~mL} / \mathrm{kg}$ of $0.9 \%$ saline solution (at $37^{\circ} \mathrm{C}$ ) instilled via the tracheal tube. After $30 \mathrm{~s}$, saline was drained out of the lungs and ventilation recommenced. This process was repeated until the $\mathrm{PaO}_{2}: \mathrm{F}_{\mathrm{I}} \mathrm{O}_{2}$ ratio $(\mathrm{PFR})<300 \mathrm{mmHg}$ $(40 \mathrm{kPa})$ was achieved at a PEEP of $5 \mathrm{cmH}_{2} \mathrm{O}$ and $\mathrm{F}_{\mathrm{I}} \mathrm{O}_{2}$ of 0.7 . 


\section{Study protocol}

A series of $20 \mathrm{~s}$ breath-holding manoeuvres was performed at different PEEP levels [range 0 to $20 \mathrm{cmH}_{2} \mathrm{O}$ ] and at end-inspiratory pressures associated with a $V_{\mathrm{T}}$ of $10 \mathrm{~mL} /$ $\mathrm{kg}$. Whole lung $\mathrm{CT}$ scans and continuous $\mathrm{PaO}_{2}$ data were recorded simultaneously during the breath-holding manoeuvres.

\section{CT image acquisition and analysis}

CT images were acquired with a Somatom Definition Flash (Siemens, Erlangen, Germany), used as a gold standard to measure lung volumes. Tube voltage was $80 \mathrm{kV}$, with $364 \mathrm{~mA}$ current and $64 \times 60 \mathrm{~mm}$ collimation. Reconstituted voxel dimensions were $0.5 \times 0.5 \times 5 \mathrm{~mm}$.

CT image analysis was performed using 3D Slicer v4.10.2 [25] (https://www.slicer.org), as presented elsewhere [26]. Aerated lung volume was calculated according to mean Hounsfield unit (HU) density within the segmented lung volume.

The HU boundaries were water with a density of $1 \mathrm{~g} \mathrm{~cm}^{-3}(0 \mathrm{HU})$ and air with a density of $0 \mathrm{~g} \mathrm{~cm}^{-3}(-1000 \mathrm{HU})$. Gas volume was computed as in Chiumello et al. [27]:

$$
V_{\mathrm{CT}}=\frac{-\mathrm{CT} \text { density }(\mathrm{HU})}{1000} \times \text { segmented lung volume }
$$

\section{Continuous measurement of $\mathrm{PaO}_{2}$ and mathematical modelling}

$\mathrm{PaO}_{2}$ was recorded with a fibre optic sensor based on luminescence quenching by oxygen of a fluorophore embedded in a polymer material, polymethyl-methacrylate [23, $28-31]$, inserted in a carotid artery via a standard arterial catheter. The sensor has a response time $\sim 100 \mathrm{~ms}$ and data were recorded continuously at $10 \mathrm{~Hz}$. Technical properties of this sensor are presented elsewhere [30, 32].

As illustrated in Fig. 1, the lung was assumed to perform as a single compartment with a constant oxygen uptake. Here the rate of $\mathrm{PaO}_{2}$ decline is inversely proportional to lung volume, and directly proportional to the rate of oxygen uptake by the pulmonary circulation $[17,18]$. Based on the equation presented in Fig. 1, predicted lung volume available for gas exchange can be calculated on the basis of measured oxygen uptake and rate of $\mathrm{PaO}_{2}$ decline during each breath-hold manoeuvre. The single compartment assumption was supported by stable airway pressure and flow, and EIT signal during the relevant

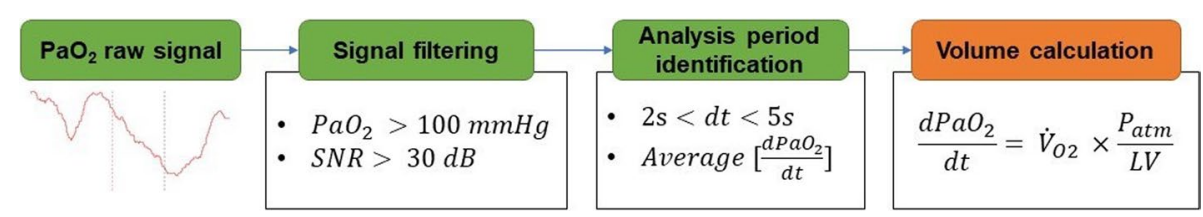

Fig. 1 Algorithm to calculate lung volume available for gas exchange. The text in the coloured boxes summarises the main steps in the algorithm leading to the equation used for the calculation of lung volume available for gas exchange. The text in the white boxes presents the physiological and signal conditions imposed a priori for the automatic processing and analysis of the raw $\mathrm{PaO}_{2}$ signal, necessary for a bias-free selection of the representative period that was used for the automatic calculation of lung volume available for gas exchange. Additional methodological details are presented in the methods. $\mathrm{PaO}_{2}$ arterial partial pressure of oxygen; SNR: signal-to-noise ratio; $V_{02}$ : oxygen uptake; $P_{\text {atm }}$ : atmospheric pressure; LV: lung volume 
period of apnoea, as illustrated in Fig. 2. In this single compartment assumption, the rate of alveolar oxygen change equals the difference between the rates of input via ventilation during inspiration and output via continuous uptake by the pulmonary circulation and elimination during expiration [19]. Pigs' metabolism (e.g. heart rate, respiration and oxygen uptake) was stable during the experimental protocol.

The novel $\mathrm{PaO}_{2}$ signal processing technique proposed here is based on the calculation of $\mathrm{PaO}_{2}$ gradient between two random time points in the $\mathrm{PaO}_{2}$ signal during the overall breath-hold period, defined as the period with no airway flow. This iterative analysis was repeated a hundred times for each of the breath-hold manoeuvres, leading to the algorithm proposed here (Fig. 1), which identifies the period of linear decline on which the calculations to estimate lung volume available for gas exchange were based.

The linear $\mathrm{PaO}_{2}$ signal recorded in the last $2-5 \mathrm{~s}$ of each breath-holding manoeuvre was used to calculate the lung volume; an example is illustrated in Fig. 2. The airway flow, pressure and EIT signals were stable in the periods considered for analysis. The maximum analysis period was limited to $5 \mathrm{~s}$ to exclude transient changes in pulmonary ventilation, perfusion and their distributions, which might have occurred at the beginning of the breath-holding manoeuvres. These transient changes could have temporarily affected the linearity of the $\mathrm{PaO}_{2}$ rate of decline and would be overlooked by a singlecompartment model of the respiratory system, hence would affect the accuracy of lung volume calculation. If the $\mathrm{PaO}_{2}$ decline was linear for $5 \mathrm{~s}$, then a 5-s period was used to

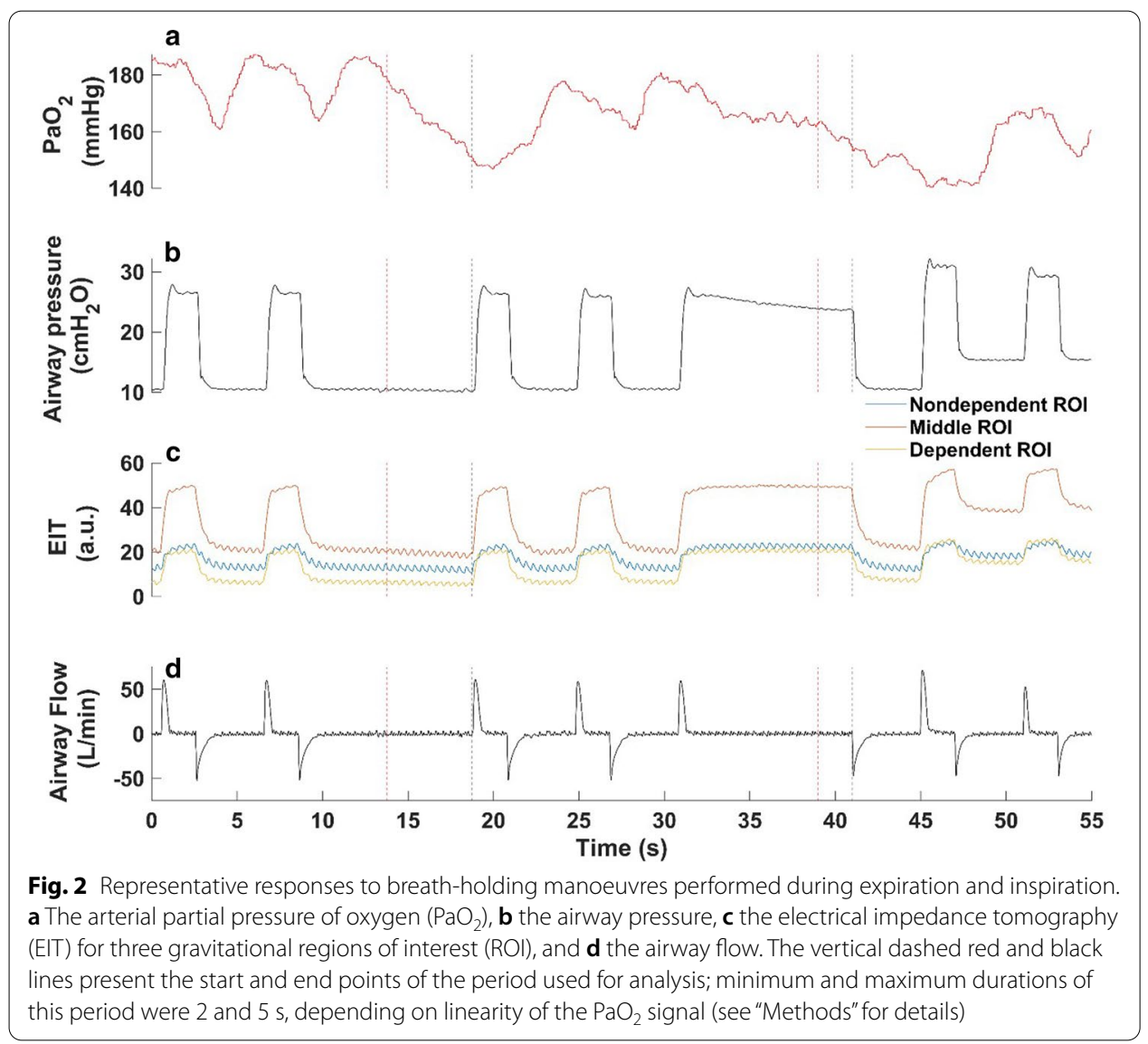


calculate the lung volume. Alternatively, a period shorter than $5 \mathrm{~s}$ was used for analysis, where a minimum period of at least $2 \mathrm{~s}$ was required because shorter periods were associated with relatively low signal-to-noise ratios and reduced accuracy and confidence. Breath-holding manoeuvres where $\mathrm{PaO}_{2}$ signal-to-noise ratio was $<30 \mathrm{~dB}$ were excluded from the analysis, as were those manoeuvres when $\mathrm{PaO}_{2}$ signal was smaller than $100 \mathrm{mmHg}$ because of haemoglobin desaturation, which itself reduces the rate of $\mathrm{PaO}_{2}$ decline. For these two conditions combined, $20 \%$ of the data were excluded. Overall, this standardised procedure first filtered the raw signal to exclude cases where low signal-to-noise ratio and haemoglobin saturation reduction could have confounded the analysis, and then automatically calculated lung volume available for gas exchange, using an operator- and patient-independent approach to avoid subjectivity and bias.

\section{Statistical analysis}

Linear regression, Bland-Altman and polar plots were used to assess the relationship and agreement between absolute lung volumes and their changes measured with CT and with $\mathrm{PaO}_{2}$ rate of decline [33, 34]. The linear relationship between measurements was analysed using linear mixed effects modelling with variation caused by different animals considered as a random effect. Conditional $R^{2}$ values based on the entire model are reported [35]. Change in lung volumes $(\Delta V)$ were calculated from their values measured at different airway pressure levels, and compared using four-quadrant and polar plots [36], where concordance was assumed adequate within $\pm 30^{\circ}$ of the horizontal. Statistical analyses were performed in Matlab v2018b (Mathworks, MA, USA).

\section{Results}

A total number of 146 paired lung volume measurements were analysed in 6 control pigs and 13 saline lavage lung injury pig models at five different PEEP levels.

Figure 3 shows lung volumes and their PEEP-associated changes measured by $\mathrm{PaO}_{2}$ and CT. Overall, lung volumes available for gas exchange measured by $\mathrm{PaO}_{2}$ rate of decline $\left(V_{\mathrm{PaO} 2}\right)$ and those measured by whole-lung $\mathrm{CT}\left(V_{\mathrm{CT}}\right)$ increased with PEEP in the saline lavage model and in control animals. $V_{\mathrm{PaO} 2}$ were greater than $V_{\mathrm{CT}}$ at PEEP $0 \mathrm{cmH}_{2} \mathrm{O}$ in the saline lavage lung injury model during end-expiratory (volume difference $=270(96) \mathrm{mL}$ ) and the associated end-inspiratory (volume difference $=319(234)$ $\mathrm{mL}$ ) breath-holding manoeuvres. Additional file 1: Table S1 details these $V_{\mathrm{PaO} 2}$ and $V_{\mathrm{CT}}$ and their differences. Additional file 1: Table S2 shows details of multiple replicate measurements and that the mean coefficient of variation for $\mathrm{V}_{\mathrm{PaO} 2}$ repeated measurements within animal was less than $10 \%$ in both the control animals and in the saline lavage lung injury model.

\section{Absolute lung volumes}

Figure 4 shows the positive correlations between $\mathrm{V}_{\mathrm{PaO} 2}$ and $\mathrm{V}_{\mathrm{CT}}$. Correlation values were 0.90 and 0.64 , and $R^{2}$ were 0.88 and 0.70 , respectively, in the control pigs (Fig. $4 \mathrm{a}$ ) and in the saline lavage lung injury model (Fig. 4c). The mean bias ( $\pm 95 \%$ limits of agreement) for $\mathrm{V}_{\mathrm{PaO} 2}$ and $\mathrm{V}_{\mathrm{CT}}$ was $-84 \mathrm{~mL}( \pm 301 \mathrm{~mL})$ in control pigs (Fig. $\left.4 \mathrm{~b}\right)$, and $2 \mathrm{~mL}$ $( \pm 405 \mathrm{~mL}$ ) in the saline lavage lung injury model (Fig. $4 \mathrm{~d}$ ), where the mean bias tended to decrease at larger lung volumes. 


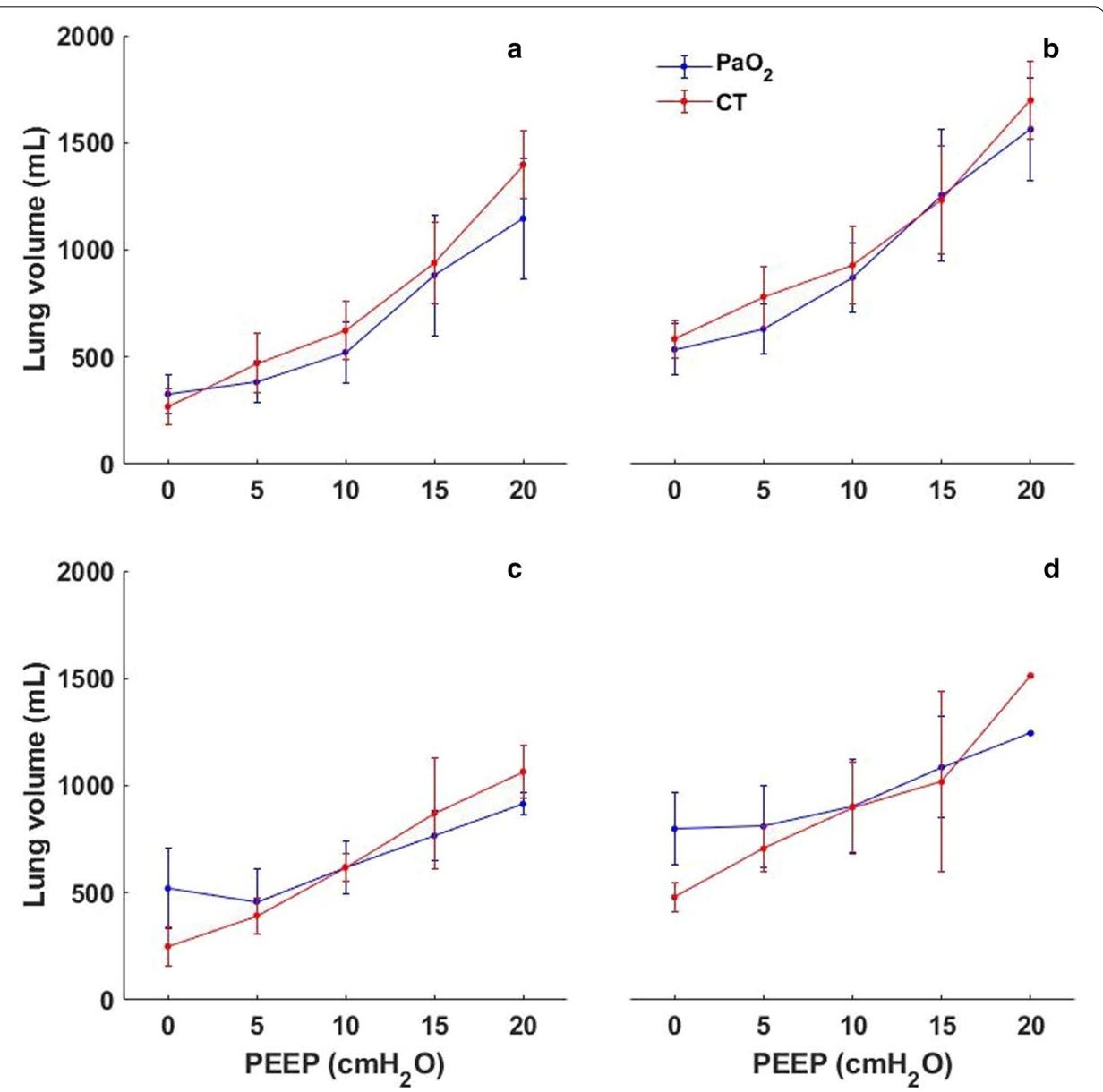

Fig. 3 Lung volume measurement (mean $\pm \mathrm{SD}$ ) from $\mathrm{PaO}_{2}$ analysis and $\mathrm{CT}$ imaging at different PEEP levels during incremental PEEP titration. $V_{\mathrm{PaO} 2}$ and $V_{\mathrm{CT}}$ measurements in the control animals during a apnoea at end-expiration and $\mathbf{b}$ end-inspiration. $V_{\mathrm{PaO} 2}$ and $V_{C T}$ measurements in the saline lavage lung injury model during $\mathbf{c}$ apnoea at end-expiration and $\mathbf{d}$ end-inspiration. Additional file 1: Table S2 provides full details of volumes measured and probabilities of difference

\section{Lung volume changes}

Figure 5 shows $100 \%$ concordance and positive correlations between $\Delta V_{\mathrm{PaO} 2}$ and $\Delta V_{\mathrm{CT}}$. Correlation values were 0.82 and 0.59 , and $R^{2}$ were 0.75 and 0.76 , respectively, in the control pigs (Fig. 5a) and in the saline lavage lung injury model (Fig. 5c). The mean angular bias ( $\pm 95 \%$ radial limits of agreement) for polar agreement between $V_{\mathrm{PaO} 2}$ and $V_{\mathrm{CT}}$ was $-4^{\circ}\left( \pm 19^{\circ}\right)$, with a concordance of $97 \%$ in the control pigs $(5 \mathrm{~b})$, and $-9^{\circ}\left( \pm 33^{\circ}\right)$, with a concordance of $86 \%$ in the saline lavage lung injury model (5d).

\section{Discussion}

This pre-clinical study presents a novel bedside method to monitor lung volume available for gas exchange, and it demonstrates the positive correlation, agreement and small bias between $V_{\mathrm{PaO} 2}$ and $V_{\mathrm{CT}}$ in a mechanically ventilated pig saline lavage lung injury model and in control pigs during breath-holding manoeuvres. While these results were 

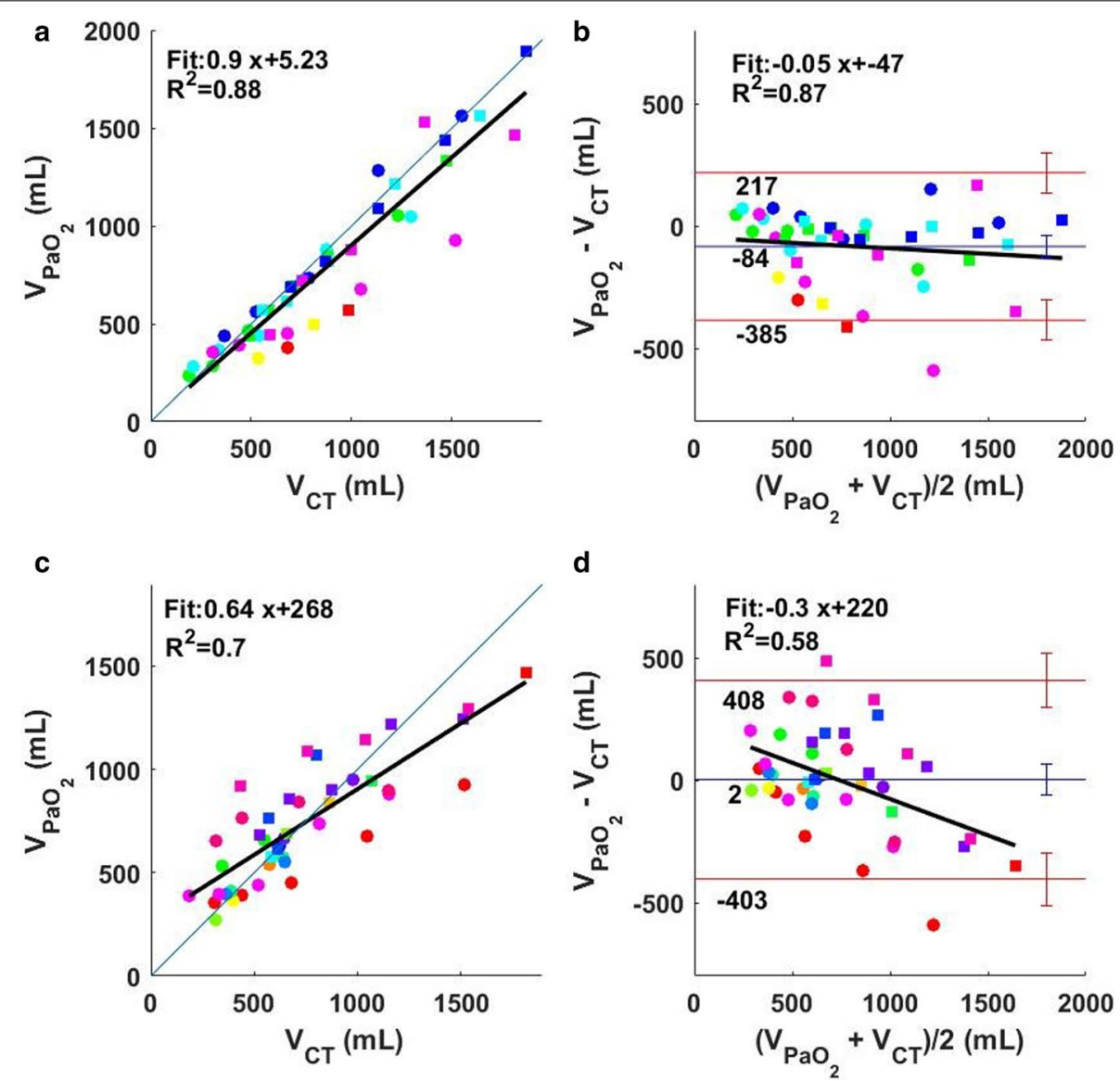

Fig. 4 Linear regression and Bland-Altman analyses for absolute volume measurements of $V_{\mathrm{PaO2}}$ and $V_{C T}$ in the control animals $(\mathbf{a}, \mathbf{b})$, and in the saline lavage lung injury model $(\mathbf{c}, \mathbf{d})$. Individual points represent a paired set of measurements at different PEEP levels (individual values in Additional file 1: Table S1). Each colour shows results from one animal. Circles and squares represent volumes measured, respectively, during end-expiratory and end-inspiratory apnoea. $\mathbf{a}, \mathbf{c}$ Black solid lines are the regression lines, and the blue lines are the identity lines. $\mathbf{b}, \mathbf{d}$ Black solid lines are the Bland-Altman plots'regression lines, blue lines are the mean bias and red lines are the upper and lower limits of agreement ( $\pm 1.96 \mathrm{SD}$ ) with 95\% confidence interval

associated with relatively small limits of agreement at low lung volumes, the limits of agreement indicated reduced accuracy at larger lung volumes, outside the $<5 \%$ recommendation [37]. The relatively smaller radial limits of agreement indicated a greater accuracy in the measurements of $\Delta V_{\mathrm{PaO} 2}$ and $\Delta V_{\mathrm{CT}} . V_{\mathrm{PaO} 2}$ results variability within animal was $<10 \%$, within the reported acceptable limits of coefficient of variation [38].

The single-compartment model assumes that the air volume measured contributes to gas exchange in the lung (i.e. ventilated and perfused alveolar volume), whereas the air volume measured with $\mathrm{CT}$ imaging includes dead spaces. It is possible that this difference between techniques has contributed to the observed $\mathrm{CT}$ overestimation of absolute lung volume, especially at larger volumes in the saline lavage lung injury model, where greater volumes of air trapped behind closed airways may be present [39], as well as gas within conducting airways. At low lung volumes, especially at PEEP $0 \mathrm{cmH}_{2} \mathrm{O}$ after saline lavage, it is possible that the HU range for non-aerated lung included a portion 


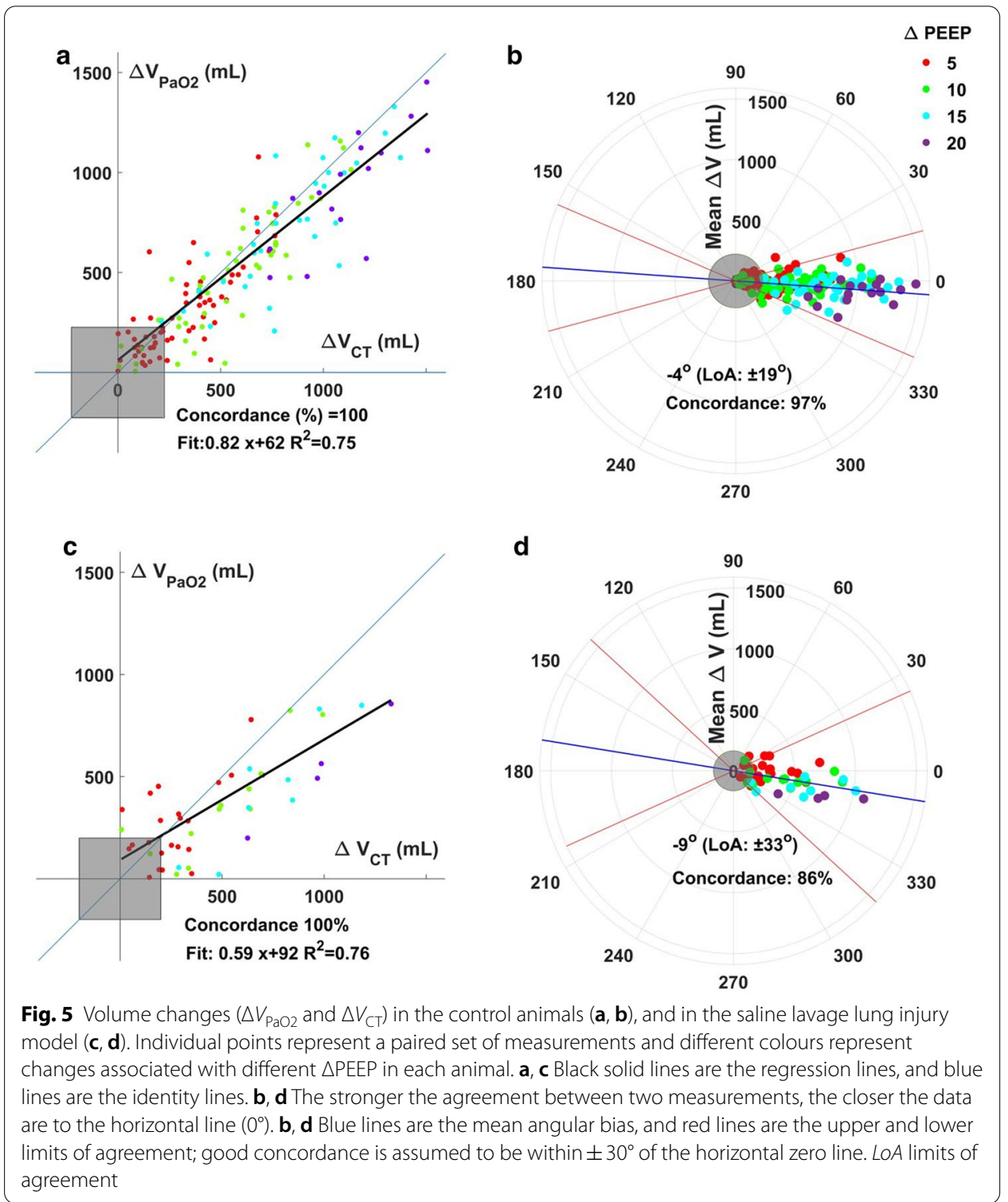

of lung that had at least a degree of ventilation and perfusion, hence contributed to gas exchange. Here, CT may not clearly distinguish between atelectatic regions not contributing to gas exchange, and regions with a very low ventilation and perfusion ratio $(V / Q)$. For example, $V_{\mathrm{CT}}$ at PEEP $5 \mathrm{cmH}_{2} \mathrm{O}$ could include volumes from the ideal alveolus and regions with a high $V / Q$ (i.e. alveolar dead space), while $V_{\mathrm{PaO} 2}$ would include volumes from the ideal alveolus and regions with a low $V / Q$. When PEEP is reduced to $0 \mathrm{cmH}_{2} \mathrm{O}$, $V_{\mathrm{CT}}$ would be reduced both by the loss of high $\mathrm{V} / \mathrm{Q}$ regions, as well as by the greater proportion of atelectasis and low $V / Q$ regions. In contrast, $V_{\mathrm{PaO} 2}$ would still capture both ideal alveolus and also regions with low $V / Q$, possibly explaining the greater $V_{\mathrm{PaO} 2}$ compared with $V_{\mathrm{CT}}$. This difference between techniques was smaller when considering changes in lung volume that may be important when determining, for example, the effect of a recruitment manoeuvre on lung volume. 
The main limitations of the $V_{\mathrm{PaO} 2}$ technique include the requirement for the brief $\sim 20$-s interruption of mechanical ventilation, the assumption that the lung can be mathematically modelled as a single compartment, for $\mathrm{PaO}_{2}$ to be greater than $100 \mathrm{mmHg}$, for an accurate measurement of oxygen uptake, and for a signal-to-noise ratio $>30 \mathrm{~dB}$.

The $V_{\mathrm{PaO} 2}$ technique must be performed during a breath-holding manoeuvre because rapid pulmonary ventilation and perfusion changes occur dynamically during tidal breathing, when the lung cannot be modelled as a single compartment. In this sense, a breath-holding manoeuvre shorter than $\sim 20 \mathrm{~s}$ may be affected by transient and regional changes in pulmonary perfusion and ventilation, associated with pendelluft $[40,41]$. Similarly long (or even longer) end-inspiratory breath-holding manoeuvres may be performed for recruitment in ARDS patients [42], but end-expiratory breath-holding manoeuvres, even at PEEP $5 \mathrm{cmH}_{2} \mathrm{O}$ as in our study here, may increase the risk of greater lung collapse.

While $\mathrm{PaO}_{2}$ is normally greater than $100 \mathrm{mmHg}$ in healthy, anaesthetised patients, it is typically lower in ARDS patients, where titration of mechanical ventilation is particularly important [2]. In order to reduce the chances of lung volume underestimation caused by haemoglobin desaturation, mean $\mathrm{PaO}_{2}$ would need to be raised above $100 \mathrm{mmHg}$ for a few minutes, also as a safety precaution, for the duration of the breath-holding manoeuvre required for the measurement of lung volume via $\mathrm{PaO}_{2}$ rate of decline. This increase in $\mathrm{PaO}_{2}$ via greater $\mathrm{F}_{\mathrm{I}} \mathrm{O}_{2}$ may not always be readily achievable.

Oxygen uptake was calculated from intermittent cardiac output measurements with thermodilution and from simultaneous arterio-venous blood samples [43]. In our study, a single oxygen uptake level was used to calculate $V_{\mathrm{PaO} 2}$ across different breathholding manoeuvres in order to limit the volume of saline injections and blood samples over the $\sim 2$-h experimental period. This approach could have contributed to the observed $V_{\mathrm{PaO} 2}$ variability due to potentially overlooked changes in oxygen uptake, especially at higher lung volumes (end-inspiratory breath holds) in the saline lavage lung injury model. Here, greater positive airway pressure could have redistributed pulmonary perfusion [44] and reduced cardiac output during the breath-holding, hence reducing pulmonary oxygen uptake, possibly leading to an underestimation of lung volume. A greater accuracy would be expected with appropriate data collection timing, such as simultaneous measurement of oxygen uptake and $V_{\mathrm{PaO} 2}$.

The fibre optic oxygen sensors used for our study are not yet produced in large quantities, hence their signal-to-noise ratio may be variable. Sensors' positional changes within the arterial vessel could also reduce the signal-to-noise ratio, although these changes are unlikely to occur. Further developments in the manufacturing process of these prototype sensors are likely going to improve signal-to-noise ratio and generate more accurate $V_{\mathrm{PaO} 2}$ measurements.

The main advantages of the $V_{\mathrm{PaO} 2}$ technique include its potential use at the bedside, availability of lung volume measurement outcome within minutes, limited costs, and operator- and patient-independent results. The $V_{\mathrm{PaO} 2}$ technique was more sensitive to relative than to absolute estimation of lung volume available for gas exchange. From a clinical perspective, this sensitivity may help distinguish recruitable from nonrecruitable lung. 


\section{Conclusion}

In conclusion, lung volumes estimated from the $\mathrm{PaO}_{2}$ rate of decline during breathholding manoeuvres correlated with volumes measured by CT, but with large limits of agreement due to several confounders. The validity of this novel method needs to be confirmed in other lung injury models before it is used clinically.

\section{Supplementary Information}

The online version contains supplementary material available at https://doi.org/10.1186/s40635-020-00364-6.

Additional file 1: Table S1. Lung volume (upper part) and its changes (lower part) in both the control animals and the saline lavage lung injury model. Table $\mathbf{S 2}$. Mean (standard deviation) of the replicated volume measurements in 9 animals. An additional 50 measurements were performed, but data were not analysed due to either $\mathrm{PaO}_{2}<100$ $\mathrm{mmHg}$, or signal-to-noise ratio $<30 \mathrm{~dB}$. n: number of observations.

\section{Acknowledgements}

We are grateful to Oxford Optronix and to the staff at the Hedenstierna Laboratoriet and Radiology Department, Uppsala University Hospital, including Agneta Roneus, Kerstin Ahlgren, Mariette Anderson, Liselotte Pihl, Maria Swälas and Monica Segelsjö for their expertise and technical assistance.

\section{Authors' contributions}

DCC, JNC and FF designed the experiments. DCC, JNC, JBB, MCT and FF carried out the experiments. MCT, DCC and JNC analysed the data. MCT, DCC, JNC, GH, AL, ADF and FF interpreted the data. AL, GH and FF contributed to financial support. MCT and FF wrote the manuscript. MCT, DCC, JNC, JBB, GH, AL, ADF and FF critically revised the manuscript. All authors read and approved the final manuscript.

\section{Funding}

FF was supported by the Medical Research Council (MC_PC_17164) and The Physiological Society (Formenti 2018), AL and GH were supported by the Swedish Lung and Heart Foundation (20170531) and the Swedish Research Council (K2015-99X-2273101-4).

Availability of supporting data and materials

Data are available upon reasonable request.

\section{Ethics approval and consent to participate}

The studies were approved by the regional animal welfare ethics committee (Ref: C98/16) and adhered to the Animal Research: Reporting of in vivo Experiments guidelines.

\section{Consent for publication}

Not applicable.

Competing interests

The authors declare no competing interests.

\section{Author details}

${ }^{1}$ Nuffield Division of Anaesthetics, University of Oxford, Oxford, UK. ${ }^{2}$ Department of Engineering Science, University of Oxford, Oxford, UK. ${ }^{3}$ Centre for Human and Applied Physiological Sciences, King's College London, London, UK. ${ }^{4}$ Department of Anaesthetics, Guy's and St. Thomas' NHS Foundation Trust, London, UK. ${ }^{5}$ Hedenstierna Laboratory, Department of Medical Sciences, Uppsala University, Uppsala, Sweden. ${ }^{6}$ Hedenstierna Laboratory, Department of Surgical Sciences, Uppsala University, Uppsala, Sweden. ${ }^{7}$ Department of Biomechanics, University of Nebraska, Omaha, NE, USA.

Received: 6 August 2020 Accepted: 2 December 2020

Published online: 11 January 2021

\section{References}

1. Bellani G, Laffey JG, Pham T et al (2016) Epidemiology, patterns of care, and mortality for patients with acute respiratory distress syndrome in intensive care units in 50 countries. J Am Med Assoc 315:788-800. https://doi. org/10.1001/jama.2016.0291

2. Slutsky AS, Ranieri VM (2013) Ventilator-induced lung injury. N Engl J Med 369:2126-2136

3. Amato MBP, Meade MO, Slutsky AS et al (2014) Driving pressure and survival in the acute respiratory distress syndrome. N Engl J Med 372:747-755. https://doi.org/10.1056/NEJMsa1410639

4. Gattinoni L, Marini JJ, Pesenti A et al (2016) The "baby lung" became an adult. Intensive Care Med 42:663-673. https ://doi.org/10.1007/s00134-015-4200-8

5. Gattinoni L, Chiumello D, Caironi P et al (2020) COVID-19 pneumonia: different respiratory treatments for different phenotypes? Intensive Care Med 46:1099-1102 
6. Vasques F, Sanderson B, Formenti F et al (2020) Physiological dead space ventilation, disease severity and outcome in ventilated patients with hypoxaemic respiratory failure due to coronavirus disease 2019. Intensive Care Med. https://doi.org/10.1007/s00134-020-06197-x

7. Vogel DJ, Formenti F, Retter AJ et al (2020) A left shift in oxyhaemoglobin dissociation curve in patients with severe COVID-19. Br J Haematol. https://doi.org/10.1111/bjh.17128

8. Goligher EC, Kavanagh BP, Rubenfeld GD et al (2014) Oxygenation response to positive end-expiratory pressure predicts mortality in acute respiratory distress syndrome: a secondary analysis of the LOVS and express trials. Am J Respir Crit Care Med 190:70-76. https://doi.org/10.1164/rccm.201404-0688OC

9. Maisch S, Boehm SH, Weismann D et al (2007) Determination of functional residual capacity by oxygen washinwashout: a validation study. Intensive Care Med 33:912-916. https://doi.org/10.1007/s00134-007-0578-2

10. Di Marco F, Rota Sperti L, Milan B et al (2007) Measurement of functional residual capacity by helium dilution during partial support ventilation: In vitro accuracy and in vivo precision of the method. Intensive Care Med 33:2109-2115. https://doi.org/10.1007/s00134-007-0833-6

11. Heinze H, Eichler W (2009) Measurements of functional residual capacity during intensive care treatment: the technical aspects and its possible clinical applications. Acta Anaesthesiol Scand 53:1121-1130. https://doi.org/10.11 11/j.1399-6576.2009.02076.x

12. Mountain JE, Santer P, O'Neill DP et al (2018) Potential for noninvasive assessment of lung inhomogeneity using highly precise, highly time-resolved measurements of gas exchange. J Appl Physiol 124:615-631. https://doi. org/10.1152/japplphysiol.00745.2017

13. Bikker IG, Leonhardt S, Bakker J, Gommers D (2009) Lung volume calculated from electrical impedance tomography in ICU patients at different PEEP levels. Intensive Care Med 35:1362-1367. https://doi.org/10.1007/s0013 4-009-1512-6

14. Wolf GK, Arnold JH (2005) Noninvasive assessment of lung volume: respiratory inductance plethysmography and electrical impedance tomography. Crit Care Med 33:S163-S169. https://doi.org/10.1097/01.ccm.0000155917.39056 .97

15. Crockett DC, Tran MC, Formenti F et al (2020) Validating the inspired sinewave technique to measure the volume of the 'baby lung' in a porcine lung-injury model. Br J Anaesth 124:345-353. https://doi.org/10.1016/j.bja.2019.11.030

16. Tran MC, Crockett DC, Formenti F et al (2020) Lung heterogeneity and deadspace volume in acute respiratory distress syndrome animals using the inspired sinewave test. Physiol Meas. https://doi.org/10.1088/1361-6579/abc0b 5

17. Dubois $\mathrm{AB}$ (1952) Alveolar $\mathrm{CO}_{2}$ and $\mathrm{O}_{2}$ during breath holding, expiration, and inspiration. J Appl Physiol 5:1-12. https://doi.org/10.1152/jappl.1952.5.1.1

18. Dubois AB, Britt AG, Fenn WO (1952) Alveolar $\mathrm{CO}_{2}$ during the respiratory cycle. J Appl Physiol 4:535-548. https://doi. org/10.1152/jappl.1952.4.7.535

19. Formenti F, Bommakanti N, Chen R et al (2017) Respiratory oscillations in alveolar oxygen tension measured in arterial blood. Sci Rep 7:1-10. https://doi.org/10.1038/s41598-017-06975-6

20. Markstaller K, Eberle B, Kauczor HU et al (2001) Temporal dynamics of lung aeration determined by dynamic CT in a porcine model of ARDS. Br J Anaesth 87:459-468. https://doi.org/10.1093/bja/87.3.459

21. Cortes GA, Marini JJ (2013) Two steps forward in bedside monitoring of lung mechanics: transpulmonary pressure and lung volume. Crit Care 17:219. https://doi.org/10.1186/cc12528

22. Kilkenny C, Browne WJ, Cuthill IC et al (2013) Improving bioscience research reporting: the arrive guidelines for reporting animal research. Animals 4:35-44. https://doi.org/10.3390/ani4010035

23. Crockett DC, Cronin JN, Bommakanti $\mathrm{N}$ et al (2019) Tidal changes in $\mathrm{PaO}_{2}$ and their relationship to cyclical lung recruitment/derecruitment in a porcine lung injury model. Br J Anaesth 122:277-285. https://doi.org/10.1016/j. bja.2018.09.011

24. Lachmann B, Robertson B, Vogel I (1980) In vivo lung lavage as an experimental model of the respiratory distress syndrome. Acta Anaesthesiol Scand 24:231-236. https://doi.org/10.1111/j.1399-6576.1980.tb01541.x

25. Fedorov A, Beichel R, Kalpathy-Cramer J et al (2012) 3D Slicer as an image computing platform for the Quantitative Imaging Network. Magn Reson Imaging 30:1323-1341. https://doi.org/10.1016/j.mri.2012.05.001

26. Cronin JN, Borges JB, Crockett DC et al (2019) Dynamic single-slice CT estimates whole-lung dual-energy CT variables in pigs with and without experimental lung injury. Intensive Care Med Exp 7:59. https://doi.org/10.1186/s4063 5-019-0273-y

27. Chiumello D, Cressoni M, Chierichetti M et al (2008) Nitrogen washout/washin, helium dilution and computed tomography in the assessment of end expiratory lung volume. Crit Care 12:2-9. https://doi.org/10.1186/cc7139

28. Formenti $\mathrm{F}$, Chen R, McPeak $\mathrm{H}$ et al (2014) A fibre optic oxygen sensor that detects rapid $\mathrm{PO}_{2}$ changes under simulated conditions of cyclical atelectasis in vitro. Respir Physiol Neurobiol 191:1-8. https://doi.org/10.1016/j. resp.2013.10.006

29. Formenti F, Chen R, McPeak H et al (2015) Intra-breath arterial oxygen oscillations detected by a fast oxygen sensor in an animal model of acute respiratory distress syndrome. Br J Anaesth 114:683-688. https://doi.org/10.1093/bja/ aeu407

30. Chen R, Formenti F, McPeak H et al (2016) Experimental investigation of the effect of polymer matrices on polymer fibre optic oxygen sensors and their time response characteristics using a vacuum testing chamber and a liquid flow apparatus. Sens Actuators B Chem 222:531-535. https://doi.org/10.1016/j.snb.2015.08.095

31. Chen R, McPeak H, Formenti F, et al (2013) Optimizing sensor design for polymer fibre optic oxygen sensors. In: Proceedings of IEEE Sensors. pp 1-4

32. Chen R, Formenti F, MCPeak H et al (2014) Optimizing design for polymer fiber optic oxygen sensors. Sensors J IEEE 14:3358-3364

33. Nawarathna LS, Choudhary PK (2013) Measuring agreement in method comparison studies with heteroscedastic measurements. Stat Med 32:5156-5171. https://doi.org/10.1002/sim.5955

34. Bland JM, Altman DG (2007) Agreement between methods of measurement with multiple observations per individual. J Biopharm Stat 17:571-582. https://doi.org/10.1080/10543400701329422 
35. Nakagawa S, Schielzeth H (2013) A general and simple method for obtaining R2 from generalized linear mixedeffects models. Methods Ecol Evol 4:133-142. https://doi.org/10.1111/j.2041-210x.2012.00261.x

36. Critchley LA, Lee A, Ho AMH (2010) A critical review of the ability of continuous cardiac output monitors to measure trends in cardiac output. Anesth Analg 111:1180-1192. https://doi.org/10.1213/ANE.0b013e3181f08a5b

37. Robinson PD, Latzin P, Verbanck S et al (2013) Consensus statement for inert gas washout measurement using multiple- and single breath tests. Eur Respir J 41:507-522. https://doi.org/10.1183/09031936.00069712

38. Wanger J, Clausen JL, Coates A et al (2005) Standardisation of the measurement of lung volumes. Eur Respir J 26:511-522. https://doi.org/10.1183/09031936.05.00035005

39. Derosa S, Borges JB, Segelsjö M et al (2013) Reabsorption atelectasis in a porcine model of ARDS: regional and temporal effects of airway closure, oxygen, and distending pressure. J Appl Physiol 115:1464-1473. https://doi. org/10.1152/japplphysiol.00763.2013

40. Otis $A B$, McKerrow CB, Bartlett RA et al (1956) Mechanical factors in distribution of pulmonary ventilation. J Appl Physiol 8:427-443. https://doi.org/10.1152/jappl.1956.8.4.427

41. Tabuchi A, Nickles HT, Kim M et al (2016) Acute lung injury causes asynchronous alveolar ventilation that can be corrected by individual sighs. Am J Respir Crit Care Med 193:396-406. https://doi.org/10.1164/rccm.201505-09010C

42. Meade MO, Cook DJ, Guyatt GH et al (2008) Ventilation strategy using low tidal volumes, recruitment maneuvers, and high positive end-expiratory pressure for acute lung injury and acute respiratory distress syndrome: a randomized controlled trial. J Am Med Assoc 299:637-645. https://doi.org/10.1001/jama.299.6.637

43. Stock MC, Ryan ME (1996) Oxygen consumption calculated from the Fick equation has limited utility. Crit Care Med 24:86-90. https://doi.org/10.1097/00003246-199601000-00015

44. Cronin JN, Crockett DC, Farmery AD et al (2020) Mechanical ventilation redistributes blood to poorly ventilated areas in experimental lung injury. Crit Care Med 48:e200-e208. https://doi.org/10.1097/CCM.0000000000004141

\section{Publisher's Note}

Springer Nature remains neutral with regard to jurisdictional claims in published maps and institutional affiliations.

\section{Submit your manuscript to a SpringerOpen ${ }^{\circ}$ journal and benefit from:}

- Convenient online submission

Rigorous peer review

- Open access: articles freely available online

- High visibility within the field

Retaining the copyright to your article

Submit your next manuscript at $\boldsymbol{\Delta}$ springeropen.com 